\title{
Factors Affecting on Immunization Compliance: Iraq
}

\author{
Omer Qutaiba B Al-lela1*, Mohd Baidi Bahari², Sara K Baderden ${ }^{3}$, Amina Y Basher ${ }^{4}$, Hani Kareem \\ Hamoodi $^{5}$ \\ ${ }^{I}$ College of Pharmacy, University of Duhok (UOD), Duhok, Kurdistan region, IRAQ. \\ ${ }^{2}$ Faculty of Pharmacy, AIMST University, Kedah, MALAYSIA. \\ ${ }^{3}$ College of Pharmacy, University of Mustansiriya, Baghdad, IRAQ. \\ ${ }^{4}$ College of Health Sciences, University of Duhok (UOD), Duhok, Kurdistan region, \\ IRAQ. \\ ${ }^{5}$ Al-Nuaman Teaching Hospital, Baghdad, IRAQ.
}

Received: 1 September 2017;

Accepted: 10 October 2017

*Correspondence to:

Dr. Omer Qutaiba B. Al-lela, PhD, Department of Clinic Pharmacy, College of Pharmacy, University of Duhok (UOD),

Duhok, IRAQ

Email: omarallela@yahoo.com

Copyright: $\odot$ the author(s),publisher and licensee Indian Academy of Pharmacists. This is an openaccess article distributed under the terms of the Creative Commons Attribution Non-Commercial License, which permits unrestricted non-commercial use, distribution, and reproduction in any medium, provided the original work is properly cited.

\begin{abstract}
Objectives: To evaluate immunization status and to identify the family and child demographic factors associated with immunization rate in Iraqi children younger than two years. Method: A cross-sectional and a cluster sampling design were implemented; five hundred twenty-eight representative Iraqi families with children between 18 and 70 months of age were interviewed in five public health clinics in Mosul-Iraq. Demographic characteristics of the child and family, and the child's immunization history were obtained. Immunization rate or completeness was assessed. Risk factors for partial immunization for the 1-5-3-4-1-1 vaccine series were explored using bivariate analyses and multi-level logistic regression models. Results: Less than half of the children had one missed dose, considered as partial immunization cases. The study found significant associations of immunization completeness with fathers and mother's education level, mother's race and family income. Number of preschool children, family income, father's education, mother's education and marital status were found that strongly impacted on immunization completeness. Conclusion: There is a need to increase awareness about the benefits and importance of vaccination, as well as the harmful consequences of partial immunization.
\end{abstract}

Key word: Immunization Status; Iraqi Child; Complete Immunization; Partial Immunization; Family and Child Factors

\section{INTRODUCTION}

More than 10 million children younger than 5 years of age died every year: over $99 \%$ are in developing countries and $70 \%$ die due to vaccine-preventable infectious diseases. [1] The development of vaccines by scientific work in developed countries is very important, but it is even more important to deliver vaccines to the poorest children or uneducated families in developing countries. However, the delivery of vaccines to children in developing, low-income countries depends on financial factors, policy barriers, and other factors related to the parents and children.

In 1974, the World Health Organization (WHO) established the Expanded Program on Immunization (EPI); this program provides free vaccines in many developing 
countries. After 1974, the immunization coverage for six EPI vaccines increased from 5\% to $80 \%$. Many studies related to immunization coverage in developing countries were carried out from 1974 (EPI establishment) up until now. Although the children received immunization free of charge, the immunization status in developing countries did not achieve the immunization targets of the WHO. There are many immunization barriers or factors related to partial or non-immunized children. ${ }^{[2-9]}$

In Iraq, immunization programmes have significantly improved public health care by limiting or reducing the spread of infections. Although the Iraq immunization system has improved the vaccination rate in children younger than 2 years of age, some Iraqi children still do not receive their scheduled vaccinations. ${ }^{[10-24]}$

According to the Iraqi Ministry of Health report in 2008, an estimated 1,065,216 children still need to be vaccinated with all of the vaccines listed in the immunization schedule. In the same report, the first dose of hepatitis $B$ virus vaccine (HBV) had the highest percentage $(91.05 \%)$ of the vaccines received by children, while the third dose of the same vaccine (HBV) had the lowest percentage (68.54\%) of the vaccines received by children. ${ }^{[25]}$ Complete immunization means that children have received all of the scheduled vaccines without any missed immunization doses, whereas partial immunization means that one or more vaccination doses were missed. Where children do not receive any immunization doses, they are considered as non-immunized children. ${ }^{[2]}$

The factors and barriers that influence the immunization programme include child demographic factors and family factors. ${ }^{[27-32]}$ Other factors include competing priorities, the inconvenient locations of clinics, missed opportunities, lack of availability, lack of education, lack of appointment reminders, and fear. ${ }^{[33]}$ In the Iraqi setting, little is known about these factors and how they contribute to the problem of unimmunized children. Knowledge of the risk factors and barriers against child immunization or inadequate immunization must be included in the strategies to increase immunization compliance and rates.

\section{Methodology}

Research design: An observational non-experimental cohort study design was chosen to evaluate immunization completeness among children younger than 2 years of age and to determine associations of immunization rate with demographic characteristics and familial data. Each child had an immunization card for recording details of the immunizations received. The data from the immunization cards and from the parents was retrospectively extracted to obtain the immunization history of each individual child.

Study setting: Most of the Iraqi children received their immunization doses from general and public health clinics. Five health clinics in different areas were selected in Mosul city, Iraq. These public health clinics operate three immunization days per week (Sunday, Tuesday, and Thursday), from $9.00 \mathrm{am}$. to $2.00 \mathrm{pm}$. Approximately 25 children attend these health clinics per day. Private clinics and hospitals were not included in the setting for this study due to accessibility problems and differences in socioeconomic status.

Data collection form design: In this study, the data collection form consisted of three parts: (1) demographic characteristics of the children (age, gender, race, birth weight, and nutritional history), (2) familial data (father's education, mother's education, mother's age at delivery, mother's race, family marital status, number of preschool children, child order, medical family history, and family income), and (3) immunization schedule of the children. A child must be received the following vaccines by 2 years of age: one BCG dose, four or five polio vaccine doses (OPV), four DTP vaccine doses, three $\mathrm{HBV}$ vaccine doses, and one MMR vaccine dose. According to the World Health Organization in Iraq, ${ }^{[24]}$ each child must receive seven doses on seven occasions, where each dose consists of many types of vaccines, as shown in immunization schedule (Table 1).

The immunization status of the children was classified into two groups depending on immunization completeness: complete immunization and partial immunization. When a child received all immunization doses without any missed dose, this child was considered to have had complete immunization, whereas if a child missed at least one immunization dose, this child was considered to have had partial immunization.

Ethical considerations: The research proposal was submitted to the Iraqi Ministry of Health in Baghdad, Iraq. Approval from the $\mathrm{MOH}$ was obtained before data collection was started. A cover letter including an information sheet describing the study objectives and the time required to fill out the questionnaire was given to all parents with an attached consent form.

Data collection procedure: The first phase of this study was the collection of immunization schedule information from the children's immunization cards. The data collection was carried out during public health clinic days: Sunday, 


\begin{tabular}{|c|c|c|c|c|c|c|c|}
\hline \multirow{2}{*}{$\begin{array}{l}\text { Vaccine } \\
\text { type }\end{array}$} & \multicolumn{7}{|c|}{ Age (months) } \\
\hline & At birth & $\begin{array}{l}\text { Two } \\
\text { months }\end{array}$ & $\begin{array}{l}\text { Four } \\
\text { months }\end{array}$ & $\begin{array}{l}\text { Six } \\
\text { months }\end{array}$ & $\begin{array}{l}\text { Nine } \\
\text { months }\end{array}$ & $\begin{array}{l}\text { Fifteen } \\
\text { months }\end{array}$ & $\begin{array}{l}\text { Eighteen } \\
\text { months }\end{array}$ \\
\hline BCG & $1^{\text {st }}$ & & & & & & \\
\hline HBV & $1^{\text {st }}$ & $2^{\text {nd }}$ & & $3^{\text {rd }}$ & & & \\
\hline DTP & & $1^{\text {st }}$ & $2^{\text {nd }}$ & $3^{\text {rd }}$ & & & $4^{\text {th }}$ \\
\hline OPV & $1^{\text {st }}$ & $2^{\text {nd }}$ & $3^{\text {rd }}$ & $4^{\text {th }}$ & & & $5^{\text {th }}$ \\
\hline MMR & & & & & & $1^{\text {st }}$ & \\
\hline Measles & & & & & $1^{\text {st }}$ & & \\
\hline
\end{tabular}

\begin{tabular}{lll}
\hline \multicolumn{3}{l}{ Table 2: Immunization completeness and compliance } \\
\hline Variables & Frequency $(\mathbf{n}=\mathbf{5 2 8})$ & Percent \\
\hline Children with Complete immunization & 286 & 54.2 \\
Children with Partial immunization & 242 & 45.8 \\
\hline
\end{tabular}

Tuesday, and Thursday, from 9.00 am to $2.00 \mathrm{pm}$. The second phase of the study consisted of parent interviews. The entire process of answering the questionnaire took the parents about 15 minutes. The data obtained were checked and prepared for data analysis.

Statistical analysis of the data: The data were analysed using SPSS for windows (Statistical Package for Social Science) version 15.0 and the level of significance was set at less than 0.05 for all analyses. Descriptive statistics were used for the distribution of child demographic data, family data, and immunization completeness. The Chi-square test was used to measure associations between nominal variables. Multivariate binary logistic regression analysis was used to find the factors that predicted complete compliance. Adjusted odds ratios were used.

\section{RESULT}

Two hundred and eighty-two children were immunized with all vaccination doses; these children were considered as having had complete immunization, but less than half of the children had one or more than one missed doses and were considered as is having had partial immunization. Table 2 shows the frequencies and percentages of immunization completeness types.

In this study, the average age of the children was $43.29 \pm$ 23.2 months. The numbers of low birth weight and normal weight children were approximately equal. The numbers of male and female children were approximately equal. The percentage of Arabic children was higher than the percentage of Kurdish children. There were no significant associations between immunization completeness and weight, gender, race, birthplace or nutritional history of the children, as shown in Table 3.

The majority of the parents had received more than 18 years of education. More than half of the mothers were 20-29 years old at the time of delivery. More than half of the families had a family income of less than 1000 US\$ and less than $10 \%$ of the families had an income of more than 2000 US\$. The present study found significant associations between immunization completeness and parents' education level, mother's race and family income $(p<0.05)$. Children who had received complete immunization and partial immunization had a greater proportion of parents who had received $>18$ years of education than the other groups. Arabic mothers had a higher percentage (98.6\%) of children who had received complete immunization than Kurdish mothers. A family income of less than 400 US\$ was associated with a higher proportion of children who had received partial immunization than the other groups. No significant associations were found between the immunization completeness group and mother's age at delivery, marital status, and number of preschool children or child order, as shown in Table 4.

Variables that were significantly associated with immunization completeness were further analysed using binary logistic regression to determine their contribution to immunization completeness. Among the variables tested were demographic and familial factors, as shown in Table 5. By using logistic regression, five factors were found to be strongly associated with immunization completeness in the presence of other factors. A significant association 


\begin{tabular}{|c|c|c|c|c|}
\hline \multirow[t]{2}{*}{ Demographic data } & \multicolumn{2}{|c|}{ Immunization completeness (\%) } & \multirow[t]{2}{*}{ Total (\%) } & \multirow[t]{2}{*}{$\mathbf{P}$} \\
\hline & Partial immunization & Complete immunization & & \\
\hline Weight & & & & 0.156 \\
\hline$\geq 2500 \mathrm{~g}$ & $111(45.9)$ & $150(52.4)$ & $261(49.4)$ & \\
\hline$<2500 \mathrm{~g}$ & $131(54.1)$ & $136(47.6)$ & $267(50.6)$ & \\
\hline Gender & & & & 0.394 \\
\hline Male & $125(51.7)$ & $136(47.6)$ & $261(49.4)$ & \\
\hline Female & $117(48.3)$ & $150(52.4)$ & $267(50.6)$ & \\
\hline Race & & & & 0.107 \\
\hline Arabic & $231(95.5)$ & $281(98.3)$ & $512(97.0)$ & \\
\hline Kurdish & $11(4.5)$ & $5(1.7)$ & $16(3.0)$ & \\
\hline Nutrition history & & & & 0.065 \\
\hline Breast feeding & $141(58.3)$ & $149(52.1)$ & $290(54.9)$ & \\
\hline Artificial feeding & $34(14.0)$ & $64(22.4)$ & $98(18.6)$ & \\
\hline Bottle feeding- Normal milk & $50(20.7)$ & $60(21.0)$ & $110(20.8)$ & \\
\hline Bottle feeding- Medical milk & $17(7.0)$ & $13(4.5)$ & $30(5.7)$ & \\
\hline Total & $242(100 \%)$ & $286(100 \%)$ & $528(100 \%)$ & \\
\hline
\end{tabular}

Chi-square test, ${ }^{a} p<0.05$

was found between immunization completeness and the number of preschool children, where families who had more than three preschool children were five times more likely to benefit from immunization completeness than families with one preschool child (OR $=5.0,95 \%$ $\mathrm{CI}=1.51-16.56, \mathrm{P}=0.008)$, but there was no significant difference between families with two to three preschool children and families with one preschool child. Family income was significantly associated with immunization completeness, where a family income of more than 2000 US\$ was 3.6 times more likely to increase immunization completeness than a family income of less than 400 US\$ $(\mathrm{OR}=3.6,95 \% \mathrm{CI}=1.35-9.7, \mathrm{P}=0.01)$, but there was no significant difference between 401-1000 US\$ and less than 400 US\$. Parents' levels of education were significantly associated with immunization completeness. Father's education of more than 18 years was 19.7 times more likely to increase immunization completeness than $<13$ years of study $(\mathrm{OR}=19.7,95 \% \mathrm{CI}=4.74-81.87$, $p<0.001)$. Similarly, mother's education of more than 18 years was 9.7 times more likely to increase immunization completeness than $<13$ years of study (OR $=9.7,95 \%$ $\mathrm{CI}=3.73-25.22, p<0.001)$. Marital status was significantly associated with immunization completeness, where a family with married parents were 10.4 times more likely to benefit from immunization completeness than single parents $(\mathrm{OR}=10.4,95 \% \mathrm{CI}=1-107.5, \mathrm{P}=0.049)$.

The model created showed a significant goodness of fit as the Omnibus test of the model coefficient was highly significant $($ Chi-square $=192.885, p<0.001, \mathrm{df}=24)$, indicating that the model was worthwhile (Pallant, 2005; Tabachnick and Fidell, 2007). Also, Hosmer and Lemeshow's test, which is the most reliable test of goodness of fit, supported the goodness of fit of the model (Chi-square $=10.808, \mathrm{P}=0.211, \mathrm{df}=8$ ) (Pallant, 2005; Tabachnick and Fidell, 2007). The Cox and Snell R Square test result was 0.312 and the Nagelkerke R Square test result was 0.413 , suggesting that between $31.2 \%$ and $41.3 \%$ of the variability was explained by the set of variables entered into the model.

\section{DISCUSSION}

According to the finding, the children were vaccinated as a result of various reasons: the parents had a good perception of vaccination benefits and risks; the parents thought that the immunization was mandatory; and/or the parents knew that immunization was required for school registration or day care attendance. ${ }^{[34-35]}$

Many reasons were found for not vaccinating children or not completing the vaccination schedule; firstly, this may have been due to a lack of vaccination information among parents or providers. Inadequate information on vaccination status may lead to inappropriately timed or missed immunizations, resulting in decreased protection against diseases, increased side effects, and increased costs. ${ }^{[4]}$ Secondly, this may have been due to the immunization card or clinical records not providing a clear and complete 


\begin{tabular}{|c|c|c|c|c|}
\hline \multirow[t]{2}{*}{ Family data } & \multicolumn{2}{|c|}{ Immunization completeness (\%) } & \multirow[t]{2}{*}{ Total (\%) } & \multirow[t]{2}{*}{$\mathbf{P}$} \\
\hline & Partial immunization & Complete immunization & & \\
\hline Father's education & & & & $<0.001^{a}$ \\
\hline$<13 y r$ & $43(17.8)$ & $6(2.1)$ & $49(9.2)$ & \\
\hline $13-18 y r$ & $62(25.6)$ & $37(12.9)$ & $99(18.8)$ & \\
\hline$>18 \mathrm{yr}$ & $137(56.6)$ & $243(85.0)$ & $380(72.0)$ & \\
\hline Mother's education & & & & $<0.001^{a}$ \\
\hline$<13 y r$ & $64(26.4)$ & $16(5.6)$ & $80(15.2)$ & \\
\hline $13-18 y r$ & $73(30.2)$ & $52(18.2)$ & $125(23.7)$ & \\
\hline$>18 \mathrm{yr}$ & $105(43.4)$ & $218(76.2)$ & $323(61.1)$ & \\
\hline Mother's age at delivery & & & & 0.183 \\
\hline$\leq 19$ & $28(11.6)$ & $27(9.5)$ & $55(10.4)$ & \\
\hline $20-29$ & $151(62.4)$ & $164(57.3)$ & $315(59.7)$ & \\
\hline$>29$ & $63(26.0)$ & $95(33.2)$ & $158(29.9)$ & \\
\hline Mother's race & & & & $0.02^{\mathrm{a}}$ \\
\hline Arabic & $229(94.6)$ & $282(98.6)$ & $511(96.8)$ & \\
\hline Kurdish & $13(5.4)$ & $4(1.4)$ & $17(3.2)$ & \\
\hline Marital status & & & & 0.19 \\
\hline Married & $236(97.5)$ & $284(99.3)$ & $520(98.5)$ & \\
\hline Single parent & $6(2.5)$ & $2(0.7)$ & $8(1.5)$ & \\
\hline Number of preschool child & & & & 0.205 \\
\hline 1 & $90(37.2)$ & $110(38.5)$ & $200(37.9)$ & \\
\hline $2-3$ & $145(59.9)$ & $159(55.6)$ & $304(57.6)$ & \\
\hline$>3$ & $7(2.9)$ & $17(5.9)$ & $24(4.5)$ & \\
\hline Child order & & & & 0.846 \\
\hline $1^{\text {st }}$ & $96(39.7)$ & $110(38.5)$ & $206(39.0)$ & \\
\hline$>1^{\text {st }}$ & $146(60.3)$ & $176(61.5)$ & $322(61.0)$ & \\
\hline Family income (US\$) & & & & $0.01^{a}$ \\
\hline$\leq 400$ & $80(33.1)$ & $68(23.8)$ & $148(28.0)$ & \\
\hline $401-1000$ & $78(32.2)$ & $132(46.2)$ & $210(39.8)$ & \\
\hline $1001-2000$ & $64(26.4)$ & $65(22.7)$ & $129(24.4)$ & \\
\hline$>2000$ & $20(8.3)$ & $21(7.3)$ & $41(7.8)$ & \\
\hline Total & $242(100 \%)$ & $286(100 \%)$ & $528(100 \%)$ & \\
\hline
\end{tabular}

Chi-square test, a $p<0.05$

immunization record. The immunization card is very important for the immunization provider to be able to determine which vaccination is due on a child's visit. In addition, the immunization card is important for parents to be able to determine or check their child's immunization status. $^{[35]}$

The immunization coverage rates found in our study population are comparable to those found in developing countries, especially in the nearby countries of Turkey,
Jordan, Iran, and the Arab Gulf States. The immunization coverage levels by the same vaccines in these regions were not always similar, ${ }^{[4-6-8]}$ however, comparisons of immunization coverage between different countries are difficult due to differences in health service systems, vaccine series and immunization schedules.

The current study results are consistent with those of another study in Brazil, ${ }^{[27]}$ in which birth weight did not influence immunization status. Although boys have a 


\begin{tabular}{llll}
\hline \multicolumn{4}{l}{ Table 5: Predictors of immunization completeness in children } \\
\hline Factors & $\mathbf{P}$ & Odd ratio & $95 \% \mathbf{C l}^{*}$ \\
\hline Number of preschool children & $0.014^{\mathrm{a}}$ & & \\
$2-3$ vs. 1 & 0.503 & 0.842 & $0.51-1.39$ \\
$>3$ vs. 1 & 0.008 & 5.014 & $1.51-16.56$ \\
Family income (US\$) & $0.001^{\mathrm{a}}$ & & \\
$401-1000$ vs. $\leq 400$ & 0.756 & 1.178 & $0.42-3.3$ \\
$1001-2000$ vs. $\leq 400$ & 0.056 & 2.634 & $0.97-7.11$ \\
$>2000$ vs. $\leq 400$ & 0.010 & 3.629 & $1.35-9.7$ \\
Father's education (year) & $<0.001^{\mathrm{a}}$ & & \\
$13-18$ vs. $<13$ & 0.005 & 7.849 & $1.87-32.89$ \\
$>18$ vs. $<13$ & $<0.001$ & 19.719 & $4.74-81.87$ \\
Mother's education (year) & $<0.001^{\mathrm{a}}$ & & \\
$13-18$ vs. $<13$ & 0.024 & 3.063 & $1.16-8.07$ \\
$>18$ vs. $<13$ & $<0.001$ & 9.711 & $3.73-25.22$ \\
Marital status (Married vs. Single parent) & $0.049^{\mathrm{a}}$ & 10.410 & $1-107.5$ \\
\hline
\end{tabular}

greater chance of being vaccinated in developing countries due to cultural discrimination against girls, in the current study population there was no association between gender and immunization completeness, as in many studies in different countries, ${ }^{[6-7-27]}$ thus, it appears that there was no gender discrimination in immunization.

The results of this study among an Iraqi population are similar to those of previous studies that found an insignificant association between immunization status and race of the population. Although the association between nutritional history of the children and immunization completeness was insignificant, this study found that about $50 \%$ of the children were not breast fed, and this result is supported by other study findings which showed that $50 \%$ of all children were breastfed and that the low rate of breast feeding in Iran was related to mothers' employment outside of the home and that the employment type affected breast feeding.

A significant association was found between father's education level and immunization rate in this study, which is in agreement with the results of several studies on immunization area. ${ }^{[7-9]}$ This finding is similar to the findings of other studies ${ }^{[9]}$ in which the duration of education showed a positive effect on child vaccinations. One study in Nigeria $^{[7]}$ showed that there was no effect of education level on immunization status when other factors were controlled, which is not consistent with the findings of this study.

As shown in many studies, ${ }^{[9]}$ this study found a significant association between mother's education level and the immunization rate of the children. In contrast, previous studies ${ }^{[27]}$ showed that the education level of mothers was not associated with the immunization rate of children, which might have been due to the homogeneity of the populations in these studies. The results of the present study were similar to the results of other studies in which the duration of the mothers' education had positive effects on the vaccination of children.

The mothers' age at child delivery was considered as one of the important factors for predicting the health condition of children in previous studies. They found that the frequency of unvaccinated children was greater among older mothers, whereas other studies found the opposite situation, where the numbers of non-immunized children were greater among younger mothers. The difference in these findings might have been due to differences in the mothers' ability to provide health care for the children due to their different ages. However, there was a lack of association between mothers' age and immunization completeness in this study, which is similar to the results of other previous studies. ${ }^{[7]}$

A significant association was found between mothers' race and vaccination rate in this study. The frequency of children who received complete immunization was higher than the frequency of partial immunization among Arabic families, whereas the opposite was found among Kurdish families. Most of the parents received information from the media (television and radio), of which the majority was in the Arabic language, which could explain the abovementioned difference. The finding in this study is consistent with findings in other studies ${ }^{[35]}$ in which race was significantly associated with vaccination compliance due to different immunization schedules between different ethnic groups. 
Some previous studies found a different result, where an insignificant association was found between immunization status and race of the population under study. The result is in agreement with the finding that children who lived with two parents were 10.4 times more likely to receive complete immunization than children who lived with a single parent, as found in a previous study in Canada, ${ }^{[34]}$ the reason being that two parents have more time to devote to child health care than single parents, since a single parent might have tight time constraints.

The effect of the number of preschool children was significant, indicating that it is associated with the prediction of up-to-date immunizations. It was found that children with more than three preschool siblings were five times more likely to have received complete immunization than a single child; this result might have been due to increased parental experience and information regarding children's vaccination from the vaccinations of the three older children.

Birth order was strongly associated with immunization completeness in many studies; ${ }^{[5-9-27]}$ the significant association in these studies was due to an increase in mothers' experience with increasing numbers of children in the family. In this study, an insignificant association was found between birth order of the child and immunization completeness. Family income is one of the most powerful and persistent barriers against immunization ${ }^{[49-68]}$ The finding of this study is consistent with those of previous studies in different countries, ${ }^{[9]}$ in which a significant association was found between family income and immunization coverage, and any increase in income led to an increase in coverage, whereas other studies ${ }^{[34]}$ showed an insignificant association between family income and immunization rate.

\section{CONCLUSION}

Immunization errors occur frequently and leading to improper immunization status. This study recommended increasing effort to optimize childhood immunization. We recommend the following activities to improve immunization completeness by reducing vaccination dose errors: (1) Increase parent knowledge about vaccine benefits and risk through clinics workshop at weekend to decrease parent wariness from vaccine side effect, (2) Remind the parent for the next vaccination visit by recall notices or mobile SMS, and (3) Repeated measurement and evaluation of immunization status to protect children from errors.

\section{ACKNOWLEDGMENT}

I would like to acknowledge the institute of postgraduate's studies "IPS" / Universiti Sains Malaysia (USM)" for their support in achieving this work through the USM fellowship program.

Funding

Nil

\section{CONFLICT OF INTEREST}

All authors declare that they have no conflict of interest to disclose.

\section{Abbreviations: None}

\section{REFERENCES}

1. World Health Organization. The world health report 1998. Geneva1998.

2. Al-Shehri S, Al-Shammari S. Immunization coverage survey in eight regions of Saudi Arabia. Annals Tropical Pediatrics. 1991;11(2):181-7.

3. Al-Sheikh O, Al-Samarrai J, Al-Sumaidaie M, Mohammad S, Al-Dujaily A. Immunization coverage among children born between 1989 and 1994 in Saladdin Governorate, Iraq. Eastern Mediterranean Health J. 1999;5:933-40.

4. Ba'amer A. Coverage of and barriers to routine child vaccination in Mukalla district, Hadramout governorate, Yemen. Eastern Mediterranean Health J. 2007;16(2):223-7.

5. Cui FQ, Gofin R. Immunization coverage and its determinants in children aged 12-23 months in Gansu, China. Vaccine. 2007;25(4):664-71.

6. Nasseri K, Latifi M, Azordegan F, Shafii F. Determinants of partial participation in the immunization programmed in Iran. Social Sci and Med. 1990;30(3):379-83.

7. Odusanya O, Alufohai E, Meurice F, Ahonkhai V. Determinants of vaccination coverage in rural Nigeria. Bio Med Central Public Health. 2008;8(1):381-8.

8. Reichler M, Darwish A, Stroh G. Cluster survey evaluation of coverage and risk factors for failure to be immunized during the 1995 National Immunization Days in Egypt. International journal of epidemiology. 1998;27(6):1083-9.

9. Torun SD, Bakrc N. Vaccination coverage and reasons for non-vaccination in a district of Istanbul. Bio Med Central Public Health. 2006;6(1):125.

10. Al-lela O, Bahari M, Alabbassi M, Basher A. Right Immunization Doses Received by Pediatric Younger than 2 Years. Value in Health. 2011;14(3):A120-A.

11. Al-lela O, Bahari M, Alabbassi M, Basher A. How Many Immunization does were missed in Pediatrics Younger than 2 years? Value in Health. 2011;14(3):120-A.

12. Al-lela O, Bahari M, Alabbassi M, Basher A. Immunization Barriers and Suggested Solutions in Iraq. Value in Health. 2011;14(3):A120-A1.

13. Al-lela O, Bahari M, Alabbassi M, Saleh M, Basher A, Shafie A. PIN88 Late Immunization Doses Received by Children Younger than Two Years. Value in Health. 2011;14(7):A281.

14. Al-lela O, Bahari M, Alabbassi M, Salih M, Basher A. PIH4 Immunization Status and Families' Factors in Iraq. Value in Health. 2012;15(7):A638.

15. Al-Lela O, Bahari M, Alabbassi M, Salih M, Basher A. PIH9 Association Between Health Care Providers and Immunization Compliance in Iraq. Value in Health. 2012;15(7):A639.

16. Al-Lela O, Bahari M, Al-Abbassi M, Salih M, Basher A. Iraqi parents' views of barriers to childhood immunization. EMHJ. 2013;19:295-7.

17. Al-Lela OQ, Bahari MB, Al-Abbassi MG, Salih MR, Basher AY. Estimation of 


\section{Status And Factors Affecting on Immunization}

immunization providers' activities cost, medication cost, and immunization dose errors cost in Iraq. Vaccine. 2012;30(26):3862-6.

18. Al-lela OQ, Bahari MB, Al-abbassi MG, Salih MR, Basher AY. Influence of health providers on pediatrics' immunization rate. J Tropical Ped. 2012;58(6):441-5

19. Al-lela $O Q$, Bahari MB, Salih MR, Al-abbassi MG, Elkalmi RM, Jamshed SQ. Factors underlying inadequate parents' awareness regarding pediatrics immunization: findings of cross-sectional study in Mosul-Iraq. Bio Med Central Pediatrics. 2014;14(1):29.

20. Al-lela OQB, Bahari MB, Al-abbassi MG, Basher AY. Development of a questionnaire on knowledge, attitude and practice about immunization among Iraqi parents. J Public Health. 2011;19(6):1-7.

21. Al-lela OQB, Bahari MB, Al-Qazaz HK, Salih MR, Jamshed SQ, Elkalmi RM. Are parents' knowledge and practice regarding immunization related to pediatrics' immunization compliance? a mixed method study. Bio Med Central Pediatrics. 2014;14(1):20.

22. Awadh Al, Hassali MA, Al-lela OQ, Bux SH, Elkalmi RM, Hadi H. Immunization knowledge and practice among Malaysian parents: a questionnaire development and pilot-testing. Bio Med Central Public Health. 2014;14(1):1107.

23. Awadh AI, Hassali MA, AI-Lela OQ, Bux SH, Elkalmi RM, Hadi H. Does an educational intervention improve parents' knowledge about immunization? Experience from Malaysia. Bio Med Central Pediatrics. 2014;14(1):254

24. World Health Organization. Immunization profile-Iraq, 2009. Available from: http://apps.who.int/immunization_monitoring/en/globalsummary/ countryprofileresult.cfm?C='irq.

25. Ministry of Health-Republic of Iraq. Immunization profile report 2008.
Available from: http://moh.gov.iq/arabic/.

26. Nath B, Singh J, Awasthi S, Bhushan V, Kumar V, Singh S. KAP Study on Immunization of Children in a City of North India-A 30 Cluster Survey. J Heal Allied Sci. 2008;7(1):1-6.

27. Barreto $T$, Rodrigues L. Factors influencing childhood immunization in an urban area of Brazil. British Med J. 1992;46(4):357-61.

28. Burns I, Zimmerman R. Immunization barriers and solutions. J Family Practice. 2005;54(1):58-62.

29. Gellin B, Maibach E, Marcuse E. Do parents understand immunizations? A national telephone surveys. Pediatrics. 2000;106(5):1097-102.

30. Okamoto S, Slingsby B, Nakayama T, et al. Barriers to vaccination among Japanese medical students: Focus group interviews. Pediatrics Int. 2008;50(3):300-5.

31. Wilson T. Factors influencing the immunization status of children in a rural setting. J Pediatric Health Care. 2000;14(3):117-21.

32. Yawn B, Xia Z, Edmonson L, Jacobson R, Jacobsen S. Barriers to immunization in a relatively affluent community. J Am Board Family Practice. 2000;13(5):325-32.

33. Houseman C, Butterfoss F, Morrow A, Rosenthal J. Focus groups among public, military, and private sector mothers: insights to improve the immunization process. Public Health Nursing. 1997;14(4):235-43.

34. Duclos P. Vaccination coverage of 2-year-old children and immunization practices--Canada, 1994. Vaccine. 1997;15(1):20-4.

35. Lopreiato J, Ottolini M. Assessment of immunization compliance among children in the Department of Defense health care system. Pediatrics. 1996;97(3):308-11.

Cite this article as: Al-lela OQB, Bahari MB, Basher AY. Factors Affecting on Immunization Compliance: Iraq. J Pharm Pract Community Med. 2017;3(4):246-53. 